Interlinking of Socio-economic Problems with Environmental Problems for Appropriate

Development in Both Developed and Developing Countries

\title{
Interlinking of Socio-economic Problems with Environmental Problems for Appropriate Development in Both Developed and Developing Countries
}

\author{
Mohammad Rafiq Khan \\ Lahore School of Economics, Lahore, Pakistan \\ drrafiq@lahoreschool.edu.pk, khanmr1939@yahoo.com
}

\begin{abstract}
This article is designed to integrate the results of the studies undertaken on different frontiers by a group of researchers to address both socio-economic problems and environmental problems with a special reference to sustainable development. It also offers appropriate solutions to make sure the best use of available resources and assigns economic value to different wastes via resource recovery through material sorting, recycling and reprocessing, production of food, heat and electricity. The focus remains on techno-economic disposal of different wastes in a way to adapt them as alternative resources instead of treating them as wastes. The article concludes that the techno-economic disposal of wastes can effectively address the problems of energy and food shortage because it is based on the hypothesis that the total amount of resources in the universe remains constant although they may change from one form to another. This hypothesis provides a firm basis for sustainable development; the concept being contemporarily explored as a cure for socio-economic ills that destabilize the shaky economies. The study supports the view that a waste is no more a waste as every waste can be assigned an economic value. The integrated results of studies conducted in the context of sustainable development strongly recommend the interlinking of economic problems with environmental problems.
\end{abstract}

Keywords: multi-dimensional, approaches, energy, crises, Pakistan, sustainable, development, appropriate technology

\section{Introduction}

Earth is the abode of living beings including microbes, humans and animals. An increase in human population corresponds with an increasing need of consumer goods in the first instance and subsequently capital goods to produce these consumer goods. The demand and supply of goods becomes requisite and balance between supply and demand becomes obligatory. Any disturbance in this obligatory balance leads to economic problems. For the fulfilment of requisite needs the balance is secured through economic activities that operate on natural resources to utilize them through extraction, processing, manufacturing, transportation and other consumptions resulting in their depletion and thus a decrease in the total stock of natural resources.

The definition of natural resources is as follows, "Natural resources are useful raw materials that we get from the Earth. They occur naturally, which means that humans cannot make natural resources. Instead, we use and modify natural resources in ways that are beneficial to us." [1] 
Table 1. Some examples of natural resources and mode of their use

\begin{tabular}{cc}
\hline $\begin{array}{c}\text { Natural } \\
\text { Resource }\end{array}$ & Products or Services \\
\hline Air & Wind energy, tires \\
Fnimals & Foods (milk, cheese, steak, bacon) and clothing (wool sweaters, silk shirts, \\
Coal & leather belts) \\
Minerals & Electricity \\
Natural gas & Electricity, heating \\
Oil & Electricity, fuel for cars and airplanes, plastic \\
Plants & Wood, paper, cotton clothing, fruits, vegetables \\
Sunlight & Solar power, photosynthesis \\
\hline Water & Hydroelectric energy, drinking, cleaning \\
\hline
\end{tabular}

The relentless consumption of natural resources puts stress on the environment due to the introduction of wastes which ought to be disposed of effectively so they may not deteriorate the quality of life in their vicinities. The efficiency and effectiveness of an economic system depends in part on the supply and quality of natural and environmental resources. Environmental resources are defined as follows, "Environmental resources can be defined as elements of the human environment, and include both natural and built resources: socioeconomic, cultural and natural." [2]

The natural and environmental resource input function is central to the understanding of the relationship between economic and environmental problems. Water, soil, air, vegetative (crops, forest, etc.) and animal (Cattle, fisheries, etc.) resources are productive assets whose quality helps determine the productivity, efficiency and effectiveness of an economy. A focus on the role of environment as a producer of goods highlights the direct effect of environmental problems on economic growth. Thus economic management influences the environment and environmental quality influences the efficient working of the economy. Environmental degradation imposes costs on the economy which result in output and human capital losses [3].

\section{Major Economic Problems}

There are many problems faced by humanity at large and here are a chosen few that fall on the top of problem multiplicity list.

1. Unstable, unbalanced and shaky national and world economies.

$\begin{array}{lll}\text { SCIENTIFIC INQUIRY AND REVIEW } & \text { Issue: III } 2018 \\ \text { Volume: } \mathbf{2} \quad 2018\end{array}$


Interlinking of Socio-economic Problems with Environmental Problems for Appropriate

Development in Both Developed and Developing Countries

2. Energy deficit translating into sky-rocketing energy costs, occasional breakdowns of electricity, partial or total paralysis of industries and many others.

3. Extensive unemployment, dearth of food, clothing and shelter leading to poverty, illiteracy, malnutrition and ill health.

4. Mass unconsciousness about conservation of resources and environmental degradation.

\section{Major Environmental Problems}

The nature of everything in universe is relative. It means that every existing natural object or body is defined relative to another. When two bodies, say $\mathrm{A}$ and $\mathrm{B}$, exist in the universe, then the first law of logic known as the Law of Identity states that "A is A not B." Hence, the existence of both $\mathrm{A}$ and $\mathrm{B}$ is relative to since they are conceived, cognized and described relative to each other. The environment denotes the surroundings of an object whose existence is to be described or assessed both qualitatively and quantitatively. It also translates into the circumstances in which a particular object maintains its existence. The quality of existence is also relative; matter exists because the five senses of human beings are there to perceive its existence. Similarly, ethical characteristics are also relative in nature. If there is no existence of evil in the universe, there is no existence of good because the former is essential for defining of the latter on the basis of relativity.

Problems, in human context, are the products of the interaction between man and environment. There are different levels of environmental problems and their intensity varies with reference to their respective ecological situation/status as shown below.

3.1. Family or Household Level. The three major requisites for the smooth living and survival of a family or household are food, clothing and shelter. Food consists of different types of bread, animal flesh and vegetables as well as drinking water. Whenever a meal is prepared, it produces wastes such as vegetable off cuts, bone, dirty water etc. The vegetable off cuts and bones comprise solid waste for disposal. Similarly, water is needed for the washing of clothes, bathing etc. leading to the production of dirty water to be disposed of. Thus waste is a problem and its disposal is an environmental challenge at the primary level.

3.2. Community Level. When several families start living together in a certain area, they collectively constitute localities such as villages and colonies to be governed by social norms and laws. Thus, family A or B cannot throw their solid rubbish in the street or on the road or let the dirty water flow out freely because it will cause nuisance for others. Some organization on voluntary or obligatory basis is framed to organize the disposal of solid and liquid pollutants.

3.3. Town and City Level. Villages may grow further adding colony after colony to constitute cities. The basic environmental problem remains the same; the disposal of the wastes and keeping the environment clean but its management moves from micro to the macro level. Thus organizations such as town committees, municipal committees, corporations, metropolitan corporations etc. are created to handle the problems respectively.

3.4. Provincial or State Level. The villages, towns, cities and big cities collectively constitute provinces that include administrative districts and divisions. The environmental problems remain the same but their scale is increased to such as extent that they take the shape of mega problems addressed through bigger organizations mentioned above and through provincial or state governments, ministries and departments, Environmental Protection Departments (EPDs), Environmental Protection Agencies (EPAs) and provincial assemblies that frame environmental protection laws and environmental and high courts which interpret and implement these laws. 
3.5. Federal Level. Federal government formulates environmental control policies and laws and implements them via provincial governments which in turn operate through divisional and district administration for the implementation of these policies and laws. The federal governments of countries have to keep in view the international obligations before framing the laws. Similarly, the federal/national assemblies formulate the environmental control laws keeping in view the global environmental protection laws and these laws are handed over to the provincial governments for their implementation. The mechanics adopted at the federal level are entirely different from that at the provincial level and at other lower levels.

\subsection{International Level Problems. The examples of international level problems are global}

warming and climate change, ozone layer depletion, trans-boundary disputes etc. Because these are world level problems their management is termed as Global Environmental Management. These are addressed by the UNO through United Nations Economic and Social Council that implements laws, conventions and protocols.

The environmental issues and disputes between different nations are discussed on the platform of the World Trade Organization and if the need arises by the International Court of Justice.

\section{Causes of Problems}

The tragic history of colonialism is marked by the irrational exploitation of natural resources, extravagant use of fossil fuels to produce export products and the bulk transfer of resources south to north and from east to west to add value to the riches of the western countries. It is further distinguished by the race to enhance the macroeconomic parameters such as growth rate, GDP per capita, neo-colonialism induced by international controls and traps, unwanted economic barriers, loans and grants, forced policy frameworks, ill intentions behind the new directions, blind follow ups and lack of consistency, unwanted administrative and governing setups such as ministries, universities, policy institutes, ill intentions behind the social reforms, missing links, individual oriented set ups, inappropriate planning and projections, ill planned changes in syllabi and curricula, non-reliance on indigenous talent and expertise, lack of the right people for the right job, inappropriate administrative structures, non-implementation of laws, statutes, rules, regulations and resolutions (Example: Polluter Pays Principle), bureaucratic barriers, wastage of time and energy on activities without outcomes and a lot more.

\subsection{Impacts}

Mortality (premature deaths), morbidity (malnutrition, squalor, illness), low standards of living, decline of industry in the developing countries, increase in the demand of consumer goods and decline in supply due to shortage in production, loss in competitive advantage and dominance of poor countries' markets by others due to flood of imported foreign products, environmental degradation (air, water and solid), tug of war between the developed and the developing countries, climatic change, fixing of responsibilities and many others.

\section{Measures: Sustainable Development and Appropriate Technology as Solutions}

Economic development without environmental considerations can cause serious environmental damage impairing the quality of life of the present and future generations. The concept of "Sustainable Development" attempts to strike a balance between the demands of economic

4

SCIENTIFIC INQUIRY AND REVIEW

Volume: $\mathbf{2}$ Issue: III 2018

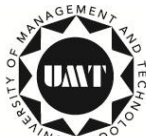


development and the need of protecting the environment. It seeks to combine the elements of economic efficiency, intergenerational equity, social concerns and environmental protection. The concept of "Appropriate Technology" offers the choice of appropriate technologies to maintain the balance between economic development and the demand for protecting the environment.

\subsection{Sustainable Development}

The concept of "Sustainable Development" is relatively recent as its idea succeeded the idea of appropriate technology first floated a few decades earlier. Its first manifestation was Agenda 21, the major and so far the most sacred document which was conceived to secure clean environment for future generations due to follow in the twenty first century. The document which may also be called a code of ethics for all nations living on earth emerged as a result of famous Earth Summit held in 1992 at Reo de Jenairo Brazil [4]. It is spread over 42 chapters, each dealing with a different aspect of social welfare in the 21 st century. The major tool recommended to achieve the ideal of Agenda 21 was sustainable development. Sustainable development means that every kind of development should be carried out in a sustainable manner, which implies economical use of resources and gives wastes an equal importance because there is nothing in this world that cannot be assigned an economic value. This is because the techno-economic disposal of waste is based on the hypothesis that the total amount of resources in the universe remains constant although they may change from one form to another. This hypothesis may in future acquire the status of a law to be known as 'Law of Conservation of Resources' just like 'Law of Conservation of Mass' and 'Law of Conservation of Energy.

This so-called law provides a firm basis for sustainable development; the concept floated as a cure of all socio-economic ills. According to the law, a waste is no more a waste as every waste can be assigned an economic value. The appropriate use of waste materials will not only translate into production and supply of important products such as bio-fuels, natural gas, heat, electricity, agricultural manure, etc. but will also equally contribute towards the cleaning of environment which is otherwise threatened by environmental pollution.

The experts of sustainable development claim that there is nothing in nature that can be called a waste as nature is capable of efficient recycling of materials within its ecological systems. The natural recycling of carbon is displayed in Figure 1. 


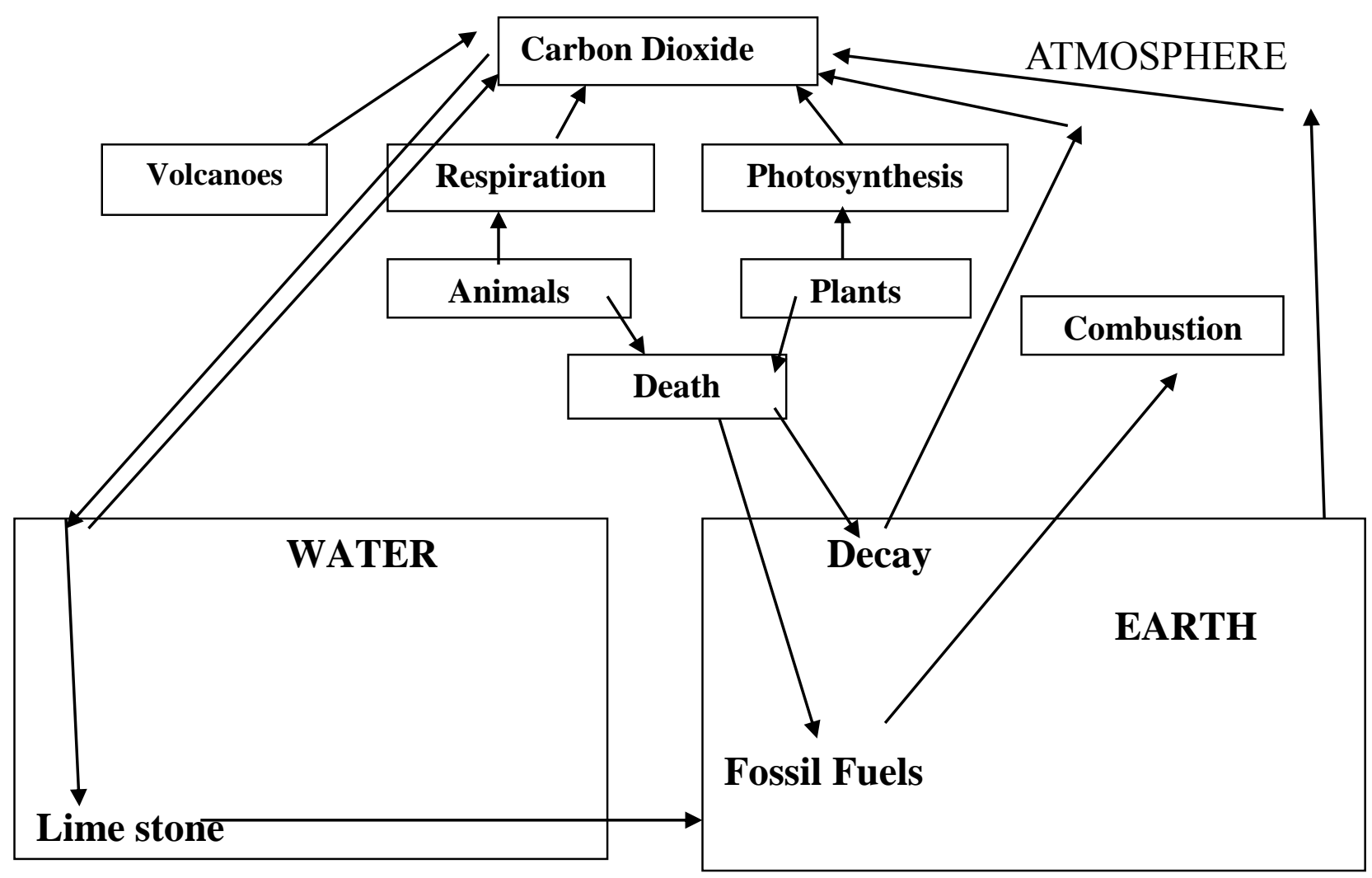

Figure 1. The Carbon Cycle (5)

The Mathematical Interpretation of Basis of conceived Law of Conservation of Resources is mathematically expressed as

Productivity $=$ Output/Input

Wastivity has been defined as the ratio of the waste to the input (6).

Thus, it is mathematically expressed as

Wastivity $=$ Waste/Input

The relationship between Input, output and waste is as follows:

Input $=$ Output + Waste

Dividing both sides by input we have;

Input/Input = Output/Input + Waste/Input

Or

Productivity + Wastivity $=1$

\section{Law of Conservation of Resources}

If productivity is increased then there is a corresponding decrease in wastage but sum of both is equal to 1 . If expressed in percentages, the sum of both should make 100. Similarly, if wastage is decreased, productivity will increase to keep the total constant. Thus the best strategy to sustain natural resources is either to reduce wastage at the source or reprocess the waste as an economic resource to keep the sum total constant.

6 
This thinking has led to the concept that resources can be conserved if processed in a sustainable manner. It may lead also to a new law stating that "The total amount of resources in the universe remains constant although they may change from one form to another". This statement is being hypothesized by the author for testing its validity and for its acceptance as law after due confirmation.

\section{Appropriate Technology}

Appropriate technology has been defined in two major ways. Its first proponent was E.F. Schumacher, the famous German philosopher who came out with the idea that technologies in operation ought to be downscaled to the midpoint of the spectrum of traditional and modern automated technologies. Its purpose was to enable poor countries to render manufacturing more labor intensive thus creating more jobs to combat the problem of poverty and unemployment [5]. The modern technologies in his opinion were both capital intensive and also unwantedly least labor intensive. The traditional technologies were also not supported because these, in spite of being highly labor intensive, operated at a very slow pace and thus could not cope with the contemporary technologies functional all over the globe. He termed the proposed technologies as "Intermediate Technologies" which in his opinion were the appropriate technologies for developing countries

The next advocate of appropriate technology for poor countries was David Livingstone Institute of Overseas Development Studies, Strathclyde University of Glasgow created under the control of Economics Department with James Pickett as its director and Eric Rahim as deputy director. They defined appropriate technology as follows (6),

"Appropriate technology is a technological sound and an economically viable technology that suits the socio-economic conditions and environment of the place where it is transferred and installed".

This definition, in spite of developing countries being the focus of the techno-economic studies, gave appropriate technology a global touch saying that it was for all and not restricted to the developing world only. Thus the definition had broad spectrum characteristics. It suggested the developing countries to adopt even most modern automated technologies provided that it's adoption was sanctioned by adequate availability of resources.

The Institute developed an "Appropriate Technology Group" that was composed of graduates of various sciences, technology, engineering and social sciences particularly economics appointed as Research Fellows and Senior Research Fellows to work on a pilot project titled as "Choice of Technique in the Developing Countries." Nine industry studies were conducted to sort out the prospects of creation of labor intensive jobs at sub-process level.

To conduct a study teams were framed and each team consisted of two researchers, usually one economist and other a scientist, technologist or an engineer. The teams collected data from almost the entire world, processed the data to frame projects at different scales of production using different choices of machinery available in different countries and finally wrote reports that were published by Scottish Academic Press, Edinburgh. The current author was also a part of the group in the capacity of a post-doctoral research fellow and worked with Eric Rahim, an economist from Pakistan to investigate corrugated board and box industry. His report forms Volume 9 of David Livingstone Institute Series on Choice of Technique in the Developing countries published by Scottish Academic Press Edinburgh in 1985 (7). Two more examples of 
such studies are also being referred to for the audience [8,9]. The best about the reports was that all were written in a text style which was easily understandable in the developing countries. The author well remembers that once the institute sent a progress report to the Steering Committee, British Ministry of Oversea Development (ODM) because it was the major grant giver to the institute. The report was returned with the remarks that the text may be revised to make it understandable at the level of developing countries. The report was revised accordingly and sent to London for perusal of the committee.

\subsection{Techno-economic Disposal of Solid Waste- A Case Study as an Example}

Techno-economic disposal of solid waste can effectively address the problem of electrical shortage. This is because the techno-economic disposal of waste is based on the concept of 'Law of Conservation of Resources' which states that the total amount of resources in the universe remains constant although they may change one form to another. The production of thermoelectric power by incineration of solid waste is more than a half century old method. The author was introduced to this important technology for the first time in late 1960s or early 1970s by a young man who was doing a job in a New York Council power plant that used the incineration of municipal waste to produce thermoelectric power. He suddenly stepped in author's room in Government College Lahore where he was a lecturer and told him how the solid waste of New York was being techno-economically disposed to overcome the problem of solid pollution along with the production of electricity for the City of New York. He disappeared and reappeared next day with a shield in his hand. He told the author that he delivered a talk on production of thermoelectric power by incineration of biomass of municipal solid waste to the councilors of Lahore Municipal Corporation and they honored him with a shield as a token to the guest speaker. He was back on the job and was almost forgotten for a long period. After a long time, it was disclosed to the author (participant) in a PTV program on environment that LMC got a study done on the production of thermoelectric power by incineration of municipal solid waste of Lahore City but its recommendations were not implemented.

The next two episodes that can be quoted in the present context are visits of the postgraduate students of Government College Lahore to Rahwali Sugar Mill and Pattoki Sugar Mill. The former utilized its sugarcane solid waste popularly known as 'Bagasse' by incinerating it only as a source of heat for the multiple effect evaporators used for concentrating the clarified sugarcane juice. The excess energy dissipated in the atmosphere and was not harnessed to produce electricity. The latter was reaping both benefits; it was concentrating the juice as well as harnessing energy to produce electricity by the use of steam boilers and turbines to meet their domestic demand. These days, many sugar mills are using this technology to dispose of bagasse and produce electricity side by side.

The fourth episode started when the author became actively involved in studies in the field of Environmental Economics at Lahore School of Economics and carried out some projects on techno-economic disposal of liquid and gaseous pollutants. Suddenly, he felt that he should do something about the similar disposal of solid pollutants. At this juncture he recalled all his memories about the techno-economic disposal of solid waste through the incineration of its biomass to produce electricity. All the events were integrated and finally translated into a pilot plan to carry out a series of studies in a systematic manner. The central theme was technoeconomic disposal of solid wastes produced from an institutional to city level.

SCIENTIFIC INQUIRY AND REVIEW

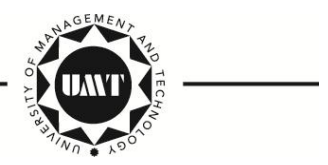


In the first phase, the economic viability of the production and disposal of solid waste was undertaken in four educational institutions: LSE, LUMS, KC and GCUL. The primary data concerning the amount and composition of solid waste was collected through successive visits to the institutions and subsequent interviews of the concerned personnel. The primary data concerning the production of thermoelectric power from solid waste such as bagasse was collected by visiting Pattoki Sugar Mill and the prices of machinery and equipment were supplied by the mill authorities which were later verified by visiting the websites of different local machinery manufacturing companies. The data were used to design the project that was subsequently appraised to determine its B/C Ratio, NPV by applying discounted cash flow techniques and the payback period (PBP) was determined by conventional method.

The results indicated that the installation of solid waste based thermoelectric power plant was not feasible for LSE [10], LUMS [11] and KC [12] but it was feasible for GCUL [13]. The data, of course, guided that the projects could be moved towards feasibility through well planned strategies.

In the second phase, the extension of work narrated above was undertaken by one of the research groups supervised by the author. The studies on village level [14], urban colony level [15] and on the City of Lahore [16] as a whole have been completed. The group has given promising messages to the residents of Lahore and to the nation at large.

The major constraint on the installation of solid waste thermoelectric power plants is the low heating value of municipal solid waste due to it being mixed with a high proportion of unwanted materials such as construction material that cannot be burnt to produce heat energy and the presence of toxic material which produces toxicity in the form of toxic pollutants [16]. An action plan may be framed to handle these problems. For example, municipal authorities can be advised to introduce the concept of separate collection of waste components at the source. The source may be a residential house, a site in an institution, a spot in a manufacturing factory and so on. The concerned authorities are expected to provide plastic bags of different colors for each spot for collecting different waste components separately. The public should be counseled to raise awareness of the value of the process with the help of media and personal contact which will guarantee a significant saving in terms of recyclables and thermoelectric power production. Moreover, it will provide a clean way of separating recyclables from non-recyclables, infectious from non-infectious, toxic from non-toxic and incinerable from non-incinerable wastes. Thus, the people carrying out this exercise will have multifold benefits through the resale of recyclables at the registered and authorized points and also through the production of thermoelectric power from the burnable biomass. Chemists and mechanical engineers can help in installing scrubbers to trap air polluting gases coming out of incinerators to avoid their absorption into the atmosphere. The biomass that will be free from construction material, dust, etc. will definitely have a higher heating value than the biomass which is mixed with other non-burnable materials.

The solid wastes can be disposed of through the alternative technique of landfills. The major requisite is that landfill should be properly designed. These are to be equipped with porous pipes for internal collection of biogas. The gas thus produced may be supplied as fuel for the production of electricity, cooking food at homes and other purposes. The residue left after the natural breakdown of biomass by anaerobic bacteria is rich in nutrients and that may be supplied to farmers as natural manure. 
In continuation of the above, the liquid pollutants may be disposed of technoeconomically producing methane, natural manure and clean water that may be supplied to agricultural farms for irrigation purposes. Waste water treatment may be studied and installed at different levels of processing such as the lowest for a locality or village and the highest for big cities like Karachi and Lahore. The designs may be better worked out by the combined effort of chemists, engineers and economists.

A single case that describes the production of thermoelectric power from the solid waste of Urban Lahore is referred below for illustration. The bases of the framework of the alternative projects are displayed in Table1.

Benefit to Cost Ratio is one of the standard references used for appraising a project. The decisive rule is that if it is more than 1 , the project is profitable and thus acceptable. If it is less than one, it is non-profitable and thus not acceptable.

Net Present Value or NPV is another standard reference. For NPV of the project the decisive rule is that the project is acceptable if NPV is positive. If it is negative, then the project is rejected.

Payback Period method works on the principle that the shorter is the time period required for the recovery of the investment in a project, the more preferable is the project being appraised. It indicates how long it takes for the returns of a project to cover its initial costs. A long payback period is not desirable. It is considered a good method of evaluation if the project under appraisal is a short term project, i.e., it takes less than five years to recover the investment.

Based on different assumptions the alternative projects evaluated are as shown in Table 1 and the results of evaluation in Table 2.

Table 2. Bases and requisites of alternative projects for production of thermoelectric power from solid waste of Urban Lahore

\begin{tabular}{lllllllll}
\hline Alternative & $\mathbf{1}$ & $\mathbf{2}$ & $\mathbf{3}$ & $\mathbf{4}$ & $\mathbf{5}$ & $\mathbf{6}$ & $\mathbf{7}$ & $\mathbf{8}$ \\
$\mathbf{S}$ & & & & & & & & \\
\hline $\begin{array}{l}\text { Solid Waste } \\
\text { /hr (m.ton) }\end{array}$ & 237.500 & 237.500 & 237.500 & 237.500 & 237.500 & 237.500 & 237.500 & 237,500 \\
& & & & & & & & \\
Cost of & Included & Exclude & Excluded & Exclude & Included & Excluded & Included & Exclude \\
Land & & $\mathrm{d}$ & & $\mathrm{d}$ & & & & $\mathrm{d}$ \\
Future & Increase & Not & Increase & Not & Increase & Increase & Increase & Included \\
Salaries & $\mathrm{d}$ & & $\mathrm{d}$ & & $\mathrm{d}$ & $\mathrm{d}$ & $\mathrm{d}$ & \\
Price / kw & Rs. 6.50/ & Rs. 6.50 & Rs. 6.50 & Rs. 6.50 & Rs. 4.00 & Rs. 4.00 & Rs 12 & Rs 12 \\
\hline
\end{tabular}

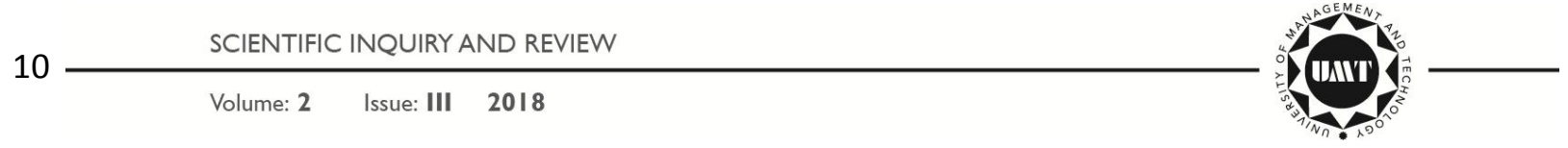


Interlinking of Socio-economic Problems with Environmental Problems for Appropriate Development in Both Developed and Developing Countries

Table 3. Comparison of alternatives at price of electricity for Urban Lahore in 2008 (US\$)

\begin{tabular}{|c|c|c|c|c|}
\hline Alt & $\begin{array}{cc}\text { PV of Benefits- PV of Costs- } & \text { B/C } \\
\text { Rs. } & \text { Rs. }\end{array}$ & $\begin{array}{c}\text { Initial } \\
\text { Investment-Rs }\end{array}$ & $\begin{array}{c}\text { Gross Profit- } \\
\text { (Rs) }\end{array}$ & $\begin{array}{c}\text { PBP } \\
\text { (Years) }\end{array}$ \\
\hline 1 & $29,566,234,915 \quad 5,169,500,2005.71$ & $24,396,734,7151,756,340,000$ & $4,329,928,000$ & 0.41 \\
\hline 2 & $29,566,234,9154,655,053,1876.35$ & $24,911,181,7281,756,340,000$ & $4,329,928,000$ & 0.41 \\
\hline 3 & $29,566,234,9155,069,500,2005.83$ & $24,496,734,7151,656,340,000$ & $4,329,928,000$ & 0.38 \\
\hline 4 & $29,566,, 234,9154,555,713,1876.48$ & $25,010,521,7281,656,340,000$ & $4,329,928,000$ & 0.38 \\
\hline 5 & $18,218,443,0385,169,500,2003.52$ & $13,048,943,8381,756,340,000$ & $2,483,128,000$ & 0.70 \\
\hline 6 & $18,218,443,0385,069,500,2003.59$ & $13,148,943,8381,656,340,000$ & $2,483,128,000$ & 0.66 \\
\hline 7 & $54,531,377,0425,169,500,20010.54$ & $49,361,876,8421,756,340,000$ & $8,392,888,000$ & 0.20 \\
\hline 8 & $54,531,377,0425,069,500,20010.75$ & $49,461,876,8421,656,340,000$ & $8,392,888,000$ & 0.19 \\
\hline
\end{tabular}

There can be hundreds of the projects like the ones narrated above. These can be identified, enlisted and studied to add significant value to national production and for the alleviation of poverty and minimization of inequality in Pakistan and also in the developing countries at large. Ultimately, the application of sustainable development may not be limited to the developing world only; it may be equally beneficial for all at the global level.

\section{A Final Tip}

Let the macroeconomic players play their game as they cannot escape the international pressures to use macroeconomic indicators as tools. They are the need of the day for sorting out short time solutions. A group should be created to identify the production oriented projects, enlist them, study them and implement them. To this end, economists should work in collaboration with technologists, engineers and scientists to learn about various technologies and their usage in depth and make their counterparts learn practical economics. This exercise will produce interdisciplinary minds with a versatile approach and the nation will have real personnel who can see both sides of the picture. A natural consequence will be that the country will also economize the use of its talented workforce. The plan framed to carry out this exercise should be long term; spread over at least two decades. 


\section{References}

[01] Study.com. What are the natural resources? - Definitions and types. Available from: http://study.com/academy/lesson/what-are-natural-resources-definition-lesson-quiz.html [Accessed April 2017].

[02] Virginia Development of Transportation (VDOD). Environmental resources. Available from: http://www.250interchange.org/index.php/2013-03-20-13-49-38/10-environmental /16environmental-resources [Accessed April 2017].

[03] India Budget. Environment - Economy Linkages. Available from: http://indiabudget.nic.in/es98-99/chap1102.pdf [Accessed April 2017].

[04] Stephanie Meakin Science and Technology Division. The Rio Earth Summit: Summary of The United Nations Conference on Environment and Development Investor Words.Com, November 1992. Available from: http://www.investorwords.com/3876/productivity.htm

[05] Schumacher EF. Small is beautiful: A study of economics as if people mattered. London: Blond \& Briggs Publisher; 1973. Available from: https://en.wikipedia.org/wiki/ Small Is Beautiful

[06] Pickett J. A report on a pilot investigation of the choice of technology in developing countries. Glasgow: David Livingstone Institute of Overseas Development Studies, University of Strathclyde Glasgow; 1975.

[07] Khan MR, Rahim E. 1985. Corrugated board and box production. Edinburgh: Scottish Academic Press; 1985. (Rahim, Eric, editor. David Livingstone Institute Series on the Choice of Technique in Developing Countries; vol. 9).

[08] Keddie J, Cleghorn W. Brewing in developing countries. Edinburgh: Scottish Academic Press; 1980. (Rahim, Eric. editor. David Livingstone Institute Series on the Choice of Technique in Developing Countries; vol. 1).

[09] Bhat BA, Prenderghast, CC. 1984. Choice of Technique in Iron Founding. 1980. (Rahim, Eric. editor. David Livingstone Institute Series on the Choice of Technique in Developing Countries; vol. 8).

[10] Khan MR, Pervez F. Production of thermoelectric power from the solid wastes of Kinnaird College. Environ Monitor. 2009; IX(9\&10):14-28.

[11] Khan MR, Sheikh S. Production of Thermoelectric Power from Solid Waste: A Case of Lahore School of Economics. Int Energy J. 2010;11:51-63.

[12] Khan MR, Kamal M. Production of thermo-electric power from the solid wastes of LUMS. International Conference on Environment; 2007 December; Malaysia.

[13] Khan MR, Abbas S. Production of thermoelectric power from solid waste of Government College University, Lahore, Pakistan. Int J Innovative Sci Eng Technol. 2014;1(9):676-696

[14] Khan, MR Burhan M. Production of thermoelectric power from the solid waste of Bhangali village. IEEE Proceedings of International Conference \& Utility Exhibition 2011 on Power and Energy Systems: Issues and Prospects for Asia, 28-30 September 2011, Pattaya City, Thailand. p.1-8.

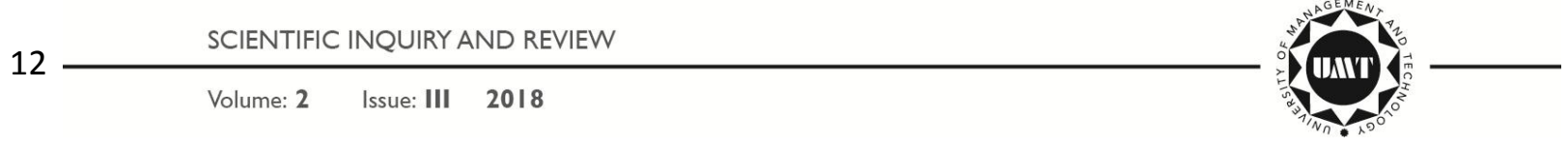


Interlinking of Socio-economic Problems with Environmental Problems for Appropriate Development in Both Developed and Developing Countries

[15] Khan MR, Zia M. Production of thermoelectric power from the solid waste of Gulberg Lahore Pakistan. Int J Innovative Sci Eng Technol. 2014;1(9):216-227,

[16] Khan MR, Tanveer H. Production of thermoelectric power from the solid waste of urban Lahore. IEEE Proceedings of International Conference \& Utility Exhibition 2011 on Power and Energy Systems: Issues and Prospects for Asia, 28-30 September 2011, Pattaya City, Thailand. p. 1-11

[17] Cheng H, Zhang Y, Meng A. Municipal solid waste fueled power generation in China: A case study of waste-to-energy in Changchun City. Environ Sci Technol. 2007;1(21):7509-15. 